\title{
Deteç̧ão do provírus da Imunodeficiência Felina em gatos domésticos pela técnica de Reação em Cadeia da Polimerase ${ }^{1}$
}

\author{
Ana Paula Ferrary Caldas ${ }^{2}$, Élcio de Souza Leal ${ }^{3}$, Eduardo Filipe Avila Silva ${ }^{4}$ e Ana \\ Paula Ravazzolo ${ }^{5}$
}

\begin{abstract}
Caldas A.P.F., Leal E.S., Silva E.F.A. \& Ravazzolo A.P. 2000. [Detection of feline immunodeficiency provirus in domestic cats by polymerase chain reaction.] Detecção do provírus da Imunodeficiência Felina em gatos domésticos pela técnica de Reação em Cadeia da Polimerase. Pesquisa Veterinária Brasileira 20(1):20-25. Centro de Biotecnologia/Faculdade de Veterinária, UFRGS, Av. Bento Gonçalves 9500, Porto Alegre, RS 91501-970, Brazil.

Feline immunodeficiency virus (FIV) infection of domestic cats is one of the most promising animal models for the infection by the human immunodeficiency virus (HIV) which causes acquired immunodeficiency syndrome (AIDS). Infected cats may develop a disease similar to that observed in AIDS patients, with increased susceptibility to opportunistic infections. In this study we used the polymerase chain reaction (PCR) to detect proviral DNA of feline immunodeficiency virus on the blood and tissue samples from cats with a clinical diagnosis of immunodeficiency. The PCR primers were used to amplify the gag gene, which is conserved among different isolates. From 40 samples analyzed, 15 were positive and 4 of them were submitted to hybridization to confirm the specificity of the amplified fragments. These results confirm the presence of FIV in domestic cats in Rio Grande do Sul, Brazil.
\end{abstract}

INDEX TERMS: Feline immunodeficiency virus, FIV, polymerase chain reaction, PCR.

SINOPSE.- A infecção de gatos domésticos pelo Vírus da Imunodeficiência Felina (FIV) é um dos modelos mais promissores para o estudo da infecção pelo vírus da imunodeficiência humana (HIV) que causa a Síndrome de Imunodeficiência Adquirida (AIDS). O FIV causa, em gatos, uma enfermidade similar àquela observada em pacientes com AIDS, sobretudo no que diz respeito ao aumento da susceptibilidade a infecções oportunistas. No presente estudo, utilizou-se a Reação em Cadeia da Polimerase (PCR), com o objetivo de detectar o provírus do FIV em gatos com sinais clínicos de imunodeficiência. $\mathrm{O}$ fragmento de DNA escolhido como alvo para am-

\footnotetext{
${ }^{1}$ Aceito para publicação em 24 de março de 1999.

${ }^{2}$ Bióloga; bolsista DTI (RHAE/CNPq), Centro de Biotecnologia, Universidade Federal do Rio Grande do Sul (UFRGS).

${ }^{3}$ Médico Veterinário, Mestrando (CAPES) do Curso de Pós-graduação em Ciências Veterinárias, UFRGS.

${ }^{4}$ Estudante de Farmácia, UFRGS; bolsista de Iniciação Científica (FAPERGS).

${ }^{5}$ Professora Adjunto, Faculdade de Veterinária e Centro de Biotecnologia, UFRGS, Av. Bento Gonçalves 9500, Cx. Postal 15005, Porto Alegre, RS 91501970. E-mail: anapr@dna.cbiot.ufrgs.br. Autor para correspondência.
}

plificação situa-se no gene gag do lentivírus felino, o qual é conservado entre as diferentes amostras do vírus. O DNA utilizado foi extraído a partir de amostras de sangue e de tecidos de animais com suspeita clínica de imunodeficiência. Das 40 amostras analisadas, 15 foram positivas, das quais 4 foram submetidas à hibridização, confirmando a especificidade dos fragmentos amplificados. Esses resultados demonstram a presença do FIV na população de gatos domésticos do Rio Grande do Sul, Brasil.

TERMOS DE INDEXAÇÃO: Vírus da Imunodeficiência Felina, FIV, Reação em Cadeia da Polimerase, PCR.

\section{INTRODUÇÃO}

$O$ Vírus da Imunodeficiência Felina (FIV), bem como a infecção do seu hospedeiro natural, o gato doméstico, tem sido descrito como um modelo potencial para o estudo da infecção pelo Vírus da Imunodeficiência Humana (HIV) (Yamamoto et al. 1988, Olmsted et al. 1989, Tompkins et al. 1991). O FIV é um lentivírus da família Retroviridae, descrito em 1987 por Pedersen e colaboradores em um gatil no qual todos os animais foram soronegativos para o vírus da leucemia felina 
(FeLV), apesar de vários deles apresentarem sinais de imunodeficiência (Pedersen et al. 1987). O vírus da imunodeficiência felina infecta principalmente gatos domésticos, sendo que em alguns estudos sorológicos detectaram-se anticorpos contra este vírus em amostras individuais de felinos selvagens, provenientes de zoológicos (Barr et al. 1989, Letcher \& O‘Connor 1991).

O FIV, devido ao seu tropismo por linfócitos $\mathrm{T} \mathrm{CD}^{+} \mathrm{e}$ $\mathrm{CD}^{+}$, linfócitos B e células do sistema nervoso central, causa uma doença - Síndrome da Imunodeficiência Adquirida em gatos - (Miyazawa et al. 1994), cujos sinais clínicos são semelhantes aos da Síndrome da Imunodeficiência Adquirida (AIDS) em humanos. A enfermidade caracteriza-se por um longo período de incubação, evolução lenta e progressiva e aparecimento tardio dos sinais clínicos. A transmissão entre os indivíduos pode ocorrer pela saliva, especificamente em casos de mordidas (Yamamoto et al. 1988, 1989, Brown et al. 1993). Na fase de infecção primária, apresenta um período de viremia de várias semanas, com linfoadenopatia generalizada, febre e neutropenia. A segunda fase caracteriza-se por um longo estágio assintomático, que pode durar vários anos, durante o qual há redução dos linfócitos T CD4+ (Novotney et al. 1990, Barlough et al. 1992). No estágio terminal, a imunodepressão é evidente, com manifestações clínicas decorrentes das infecções oportunistas (Pedersen et al.1987, Yamamoto et al. 1988). Infecções crônicas da cavidade oral e do trato respiratório são comumente observadas. (Yamamoto et al. 1989, Dow et al. 1990, Shelton,1990, 1991, Thomas et al. 1993).

Quanto à prevalência da infecção, índices de $1,2 \%$ em animais de grupos considerados de pequeno risco e de $14 \% \mathrm{em}$ grupos de alto risco têm sido relatados (Yamamoto et al. 1989). Os gatos infectados por FIV produzem anticorpos contra o vírus, os quais são normalmente detectados por testes imunoenzimáticos - ELISA (Hosie \& Jarret 1990). Além da presença de anticorpos, a infecção pode igualmente ser detectada através da presença de material genético do vírus. Considerando-se que os retrovírus têm a capacidade de integrarse ao genoma celular, sob a forma de DNA de dupla fita, é possível detetectá-los em leucócitos infectados (Rimstad \& Ueland 1992).

Os objetivos deste trabalho foram obter a confirmação da presença do FIV em gatos domésticos no Estado do Rio Grande do Sul, Brasil, e determinar as condições de utilização da técnica de diagnóstico baseada na Reação da Polimerase em Cadeia para deteç̧ão do DNA proviral. Com esta finalidade, foram utilizados "primers" complementares a uma região conservada da sequiência genômica do vírus, no gene gag. A hibridização foi realizada com o objetivo de confirmar a especificidade dos fragmentos amplificados pela PCR.

\section{MATERIAL E MÉTODOS}

\section{Amostras}

Trinta e quatro amostras de sangue foram obtidas na Faculdade de Veterinária - Laboratório de Virologia - da Universidade Federal do Rio Grande do Sul, de animais com suspeita clínica de imunodeficiência. Os órgãos de quatro animais suspeitos, submetidos à necropsia, foram coletados no Setor de Patologia da mesma Faculdade de Veterinária. Duas amostras de sangue foram obtidas na Universidade Federal de Pelotas, Rio Grande do Sul.

\section{Extração de DNA de leucócitos}

As amostras de sangue $(1 \mathrm{ml})$ coletadas com heparina foram centrifugadas por 6 min. a 4000xg em microcentrífuga. Os leucócitos da capa flogística $(100 \mathrm{ml})$ foram então coletados e adicionados de $500 \mathrm{ml}$ de TE, pH 8.0 (10 mM de Tris $\mathrm{HCl}$ e $1 \mathrm{mM}$ de EDTA). A suspensão foi centrifugada novamente a fim de obter-se um "pellet", o qual foi então ressuspendido em "K-buffer" $(10 \mathrm{mM}$ de Tris $\mathrm{HCl}$ pH 8,0, $50 \mathrm{mM}$ de $\mathrm{KCl}, 2 \mathrm{mM}$ de $\mathrm{MgCl}_{2}, 0,5 \%$ de Tween 20 e $100 \mathrm{mg} / \mathrm{ml}$ de Proteinase $\mathrm{K})$. A seguir, incubou-se a solução à $56^{\circ} \mathrm{C}$ durante $45 \mathrm{~min}$. e finalmente à $95^{\circ} \mathrm{C}$ durante $10 \mathrm{~min}$. Entre 5 e $10 \mathrm{ml}$ desta solução foram utilizados na técnica de PCR.

\section{Extração de DNA de tecidos}

Fragmentos de tecidos coletados de gatos durante as necropsias foram congelados e, posteriormente, obteve-se cortes em criostato, os quais foram fixados em lâminas de microscopia à temperatura ambiente. Depois de totalmente secos, os cortes de tecidos foram retirados por raspagem e, na forma de pó, suspendidos em tampão de digestão $(100 \mathrm{mM} \mathrm{NaCl}, 10 \mathrm{mM}$ Tris $\mathrm{HCl}$ pH 8,0, $25 \mathrm{mM}$ EDTA, $0,5 \%$ SDS e $100 \mathrm{mg} / \mathrm{ml}$ de Proteinase $\mathrm{K})$. $\mathrm{O}$ material foi incubado $1 \mathrm{~h}$ à $37^{\circ} \mathrm{C}$, seguido de 2 extrações com fenol-clorofórmio e, então, o DNA foi precipitado com etanol e acetato de sódio (Sambrook et al. 1989). Após centrifugação, o DNA precipitado foi ressuspendido em $50 \mathrm{ml}$ de água bidestilada estéril.

\section{Reação em Cadeia da Polimerase (PCR)}

As amostras foram submetidas a duas amplificações: a primeira delas, utilizando 5 - $10 \mathrm{ml}$ da solução contendo o DNA extraído e "primers" externos; e a segunda utilizando $2 \mathrm{ml}$ do produto da primeira reação, e "primers" internos (Fig. 1). Os "primers" utilizados foram: a) "primers" externos: P1 - localizado na posição 916-939 e PRT1 - localizado na posição 1375-1398; b) "primers" internos: P2 localizado na posição 1108-1129 e PRT2 - localizado na posição 1289 1310 (Rimstad \& Ueland 1992). As condições de reação foram: 5 min. à $94^{\circ} \mathrm{C}$ para desnaturação do DNA, seguido de 30 ciclos constituídos por $1 \mathrm{~min}$. à $94^{\circ} \mathrm{C}$ e $1 \mathrm{~min}$. à $68^{\circ} \mathrm{C} \mathrm{e} 90 \mathrm{seg}$. à $72^{\circ} \mathrm{C}$, completando a elongação em 8 min.à $72^{\circ} \mathrm{C}$ para os "primers" externos P1 e PRT1. Para os "primers" internos, P2 e PRT2, as condições foram: 5 min. à $94^{\circ} \mathrm{C}$ para desnaturação do DNA, seguido de 30 ciclos constituídos por $1 \mathrm{~min}$. à $94^{\circ} \mathrm{C}, 1 \mathrm{~min}$. à $66^{\circ} \mathrm{C} \mathrm{e} 90 \mathrm{seg}$. à $72^{\circ} \mathrm{C} \mathrm{e}$, para completar a elongação, 8 min.à $72^{\circ} \mathrm{C}$. $\mathrm{O}$ volume final da reação foi de $50 \mathrm{ml}$ contendo 2,5 $\mathrm{U}$ da enzima Taq DNA Polimerase (Cenbiot), dNTPs 0,2 $\mathrm{mM}, 10 \mathrm{mM}$ de Tris $\mathrm{Cl} \mathrm{pH} \mathrm{8,} 50 \mathrm{mM}$ de $\mathrm{KCl}, 3 \mathrm{mM} \mathrm{de} \mathrm{MgCl}_{2}$, os "primers" internos ou externos e a amostra de DNA (5 - $10 \mathrm{ml})$. Após eletroforese, os produtos de PCR foram visualizados em gel de agarose à $2 \%$, e corado com brometo de etídio, partindo-se de um volume de $20 \mathrm{ml}$ do produto da PCR.

\section{"Southern Blot" e Hibridização}

Os produtos de PCR de quatro amostras positivas $(11,12,16 \mathrm{e}$ 340) e um fragmento de PCR obtido a partir de amplificação do clone FIV Petaluma (34TF10) foram inicialmente resolvidos por eletroforese em gel agarose à $1,5 \%$ e transferidos para uma membrana de nylon (Hybond $\mathrm{N}^{+}$- Amersham) por capilaridade, em condições de desnaturação (Sambrook et al. 1989). Para a hibridização, utilizouse $100 \mathrm{ng}$ de DNA do clone FIV Petaluma (34TF10) como sonda específica (Talbott et al. 1989) e na detecção por quimioluminescência, o "Kit ECL - Direct Nucleid Acid Labelling and Detection 
Systems" (Amersham), conforme recomendações do fabricante. Em resumo, para a preparação da sonda, $100 \mathrm{ng}$ de DNA em um volume de $10 \mathrm{ml}$ foi desnaturado à $100^{\circ} \mathrm{C}$ por $5 \mathrm{~min}$. e imediatamente colocado no gelo. Após, acrescentou-se $10 \mathrm{ml}$ de solução de marcação ("labeling reagent" - peroxidase) e $10 \mathrm{ml}$ de solução de glutaraldeído.

A membrana de nylon foi inicialmente pré - hibridizada durante 30 minutos à $42^{\circ} \mathrm{C}$ em solução contendo $0,5 \mathrm{M}$ de $\mathrm{NaCl}$ e $5 \%$ de agente bloqueador ("blocking agent") e, a seguir, acrescentou-se a sonda. As condições de hibridização foram: incubação à $42^{\circ} \mathrm{C}$ durante 12 $16 \mathrm{~h}$, seguida de quatro lavagens, sendo duas com tampão de lavagem fornecido pelo fabricante ("primary wash buffer") à $42^{\circ} \mathrm{C}$ e duas com SSC 20X (Sambrook et al. 1989) à temperatura ambiente. A detecção do sinal referente à oxidação do "luminol" foi realizada utilizandose os agentes de detecção 1 e 2 fornecidos no Kit e expondo-se a membrana ao "Hyperfilm - ECL" durante $1 \mathrm{~min}$.

\section{RESULTADOS}

Um total de 40 amostras de DNA extraído de leucócitos e de órgãos de gatos domésticos com suspeita clínica de imunodeficiência foi submetido à técnica de PCR, sendo que 15 amostras foram positivas (Quadro 1). Destas, 8 (11, 16, $340,66,68,72,276$ e 279,) foram identificadas como positivas já na primeira reação de PCR, com os "primers" externos. Essas 8 amostras eram provenientes do sangue dos animais suspeitos.

Foi possível obter-se os dados relativos aos sinais clínicos dos animais dos quais foram coletadas algumas das amostras e observou-se que a maioria dos animais apresentava sinais de imunodeficiência, como infecções crônicas de pele e respiratórias, diarréia e em alguns casos, presença de tumores. No entanto, não foi possível estabelecer correlação entre os sinais clínicos observados e a capacidade da reação em amplificar fragmentos na primeira reação de PCR ("primers" ex-

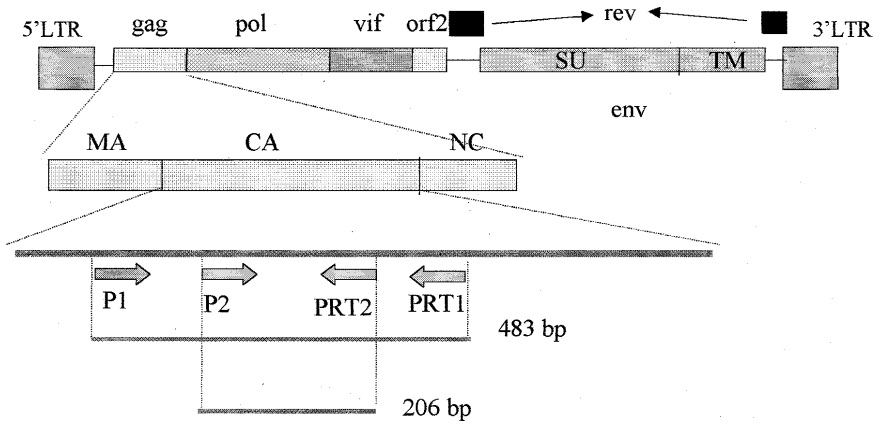

Fig. 1. Representação esquemática do genoma do vírus da imunodeficiência felina com a indicação dos "primers" utilizados nas reações de PCR. Genes estruturais, gag - pol - env (proteínas do envelope, $\mathrm{SU}=$ superfície, $\mathrm{TM}=$ transmembrana) e genes suplementares vif - orf 2 - rev. Proteínas codificadas pelo gene gag, $\mathrm{MA}=$ Matriz, $\mathrm{CA}=$ Capsídeo e $\mathrm{NC}=$ Nucleocapsídeo. P1 e PRT1 = primers externos (primeira PCR); P2 e PRT2= primers internos (segunda PCR).

ternos). Em quatro gatos, amostras 187, 276, 11 e 12, observou-se infecção respiratória. Gengivite, anemia e vômitos foram observados em mais de um dos animais dos quais se obteve as amostras positivas.

Os fragmentos compatíveis em número de pares de base com a sequência a ser amplificada, foram visualizados em gel de agarose à $2 \%$. Na primeira reação de PCR, utilizando "primers" externos, visualizou-se fragmentos de aproximadamente 480pb em 8 das 15 amostras positivas (Quadro 1, Fig. 2A e 2B). Estes "primers" foram escolhidos por situaremse no gene gag, região onde se situam seqüências conservadas do genoma FIV. A segunda PCR, utilizando os "primers"

Quadro 1. Amostras positivas para o DNA proviral do vírus da imunodeficiência felina (FIV) e sinais clínicos associados

\begin{tabular}{|c|c|c|c|c|}
\hline \multicolumn{2}{|c|}{ Amostras } & \multirow[t]{2}{*}{ Sinais clínicos } & \multicolumn{2}{|c|}{ PCR } \\
\hline Identificação & Tipo & & P1PRT1 & P2PRT2 \\
\hline 187 & Baço, pulmão & $\begin{array}{l}\text { Infecção respiratória, gengivite, dermatite, perda } \\
\text { de peso }\end{array}$ & Neg ${ }^{b}$ & $\operatorname{Pos}^{c}$ \\
\hline 66 & Sangue & $\mathrm{ND}^{\mathrm{a}}$ & Pos & Pos \\
\hline 68 & Sangue & Anemia severa & Pos & Pos \\
\hline 69 & Sangue & Massas palpáveis abdominais & Neg & Pos \\
\hline 72 & Sangue & Lesões na gengiva & Pos & Pos \\
\hline 78 & Sangue & $\begin{array}{l}\text { Infecções recidivantes na pele, emagrecimento, } \\
\text { tumores abdominais }\end{array}$ & Neg & Pos \\
\hline 157 & Sangue & ND & Neg & Pos \\
\hline 276 & Sangue & $\begin{array}{l}\text { Infecção respiratória crônica, secreção } \\
\text { ocular intensa, lesões de pele, anemia }\end{array}$ & Pos & Pos \\
\hline 279 & Sangue & Vômitos, desidratação & Pos & Pos \\
\hline 340 & Sangue & Diarréia, emagrecimento, tumores abdominais & Pos & Pos \\
\hline 10 & Gânglio & ND & Neg & Pos \\
\hline 11 & Sangue & Infecção respiratória & Pos & Pos \\
\hline 12 & Sangue & Infecção respiratória & Neg & Pos \\
\hline Cripto & Gânglio & Infecção disseminada por Cryptococcus neoformans & Neg & Pos \\
\hline 16 & Sangue & Vômitos, emagrecimento & Pos & Pos \\
\hline
\end{tabular}



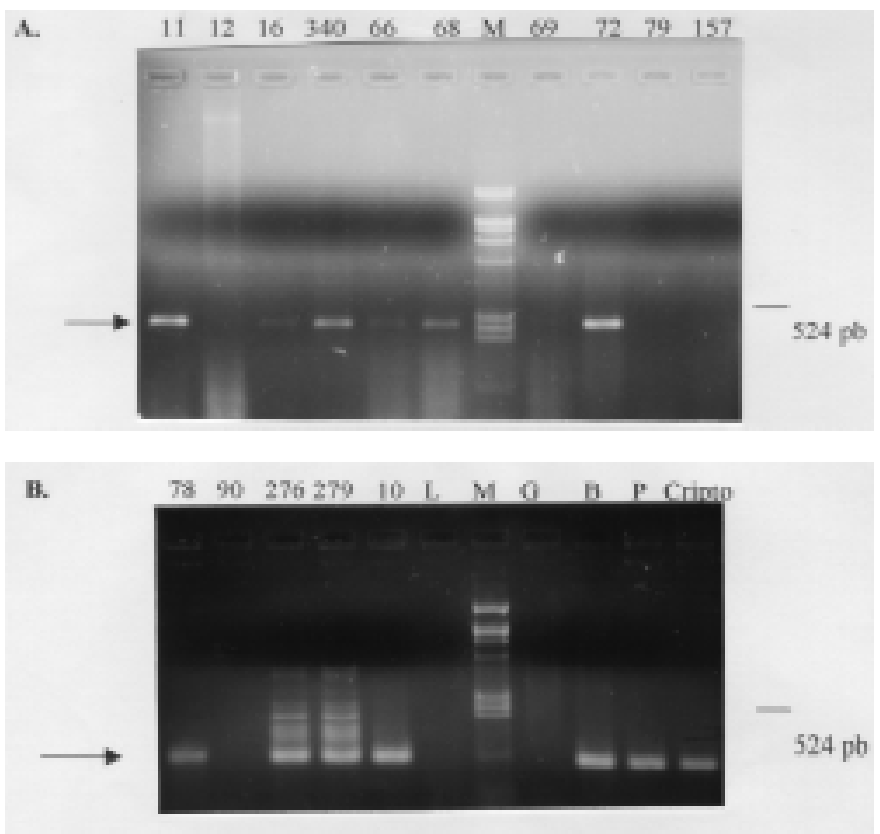

Fig. 2. Resultados obtidos na PCR com os "primers" externos. O fragmento de aproximadamente 480 pb está indicado por uma flecha à esquerda. $\mathrm{O}$ valor da direita corresponde a um fragmento do marcador. Os números e letras acima identificam as amostras $(\mathrm{G}=$ gânglio, $\mathrm{B}=$ baço, $\mathrm{P}=$ pulmão da amostra 187 ; $\mathrm{L}=$ amostra negativa).

$\mathrm{M}=$ marcador em pares de bases.
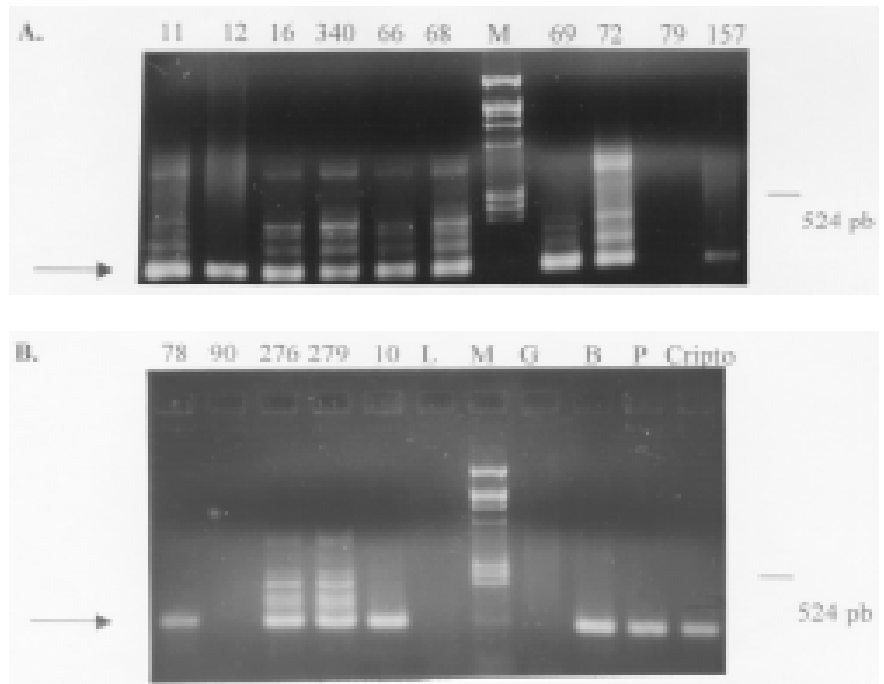

Fig. 3. Resultados obtidos na PCR com os "primers" internos. O fragmento de aproximadamente 200 pb está indicado por uma flecha à esquerda. $\mathrm{O}$ valor da direita corresponde a um fragmento do marcador. Os números e letras acima identificam as amostras $(\mathrm{G}=$ gânglio, $\mathrm{B}=$ baço, $\mathrm{P}=$ pulmão da amostra 187 ; $\mathrm{L}=$ amostra negativa).

$\mathbf{M}=$ marcador em pares de bases.

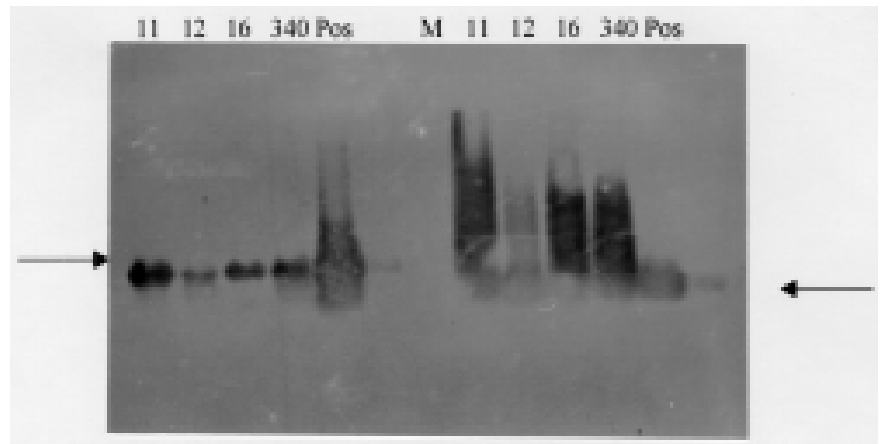

Fig. 4. Hibridização de fragmentos obtidos na PCR. Os fragmentos obtidos na PCR foram transferidos para uma membrana de nylon e hibridizados com uma sonda. As flechas indicam os fragmentos de aproximadamente 200 pb (dir) e de 480 pb (esq). Os números acima identificam as amostras; $\mathrm{M}$, o marcador e Pos, o controle positivo.

internos, permitiu detectar um maior número de amostras positivas com a presença de fragmento compatível com o esperado, de aproximadamente $200 \mathrm{pb}$ (Fig. 3A e 3B). Amostras negativas $(79,90 \mathrm{e} \mathrm{L})$ foram incluídas na reação como controles negativos (Fig. 2A, 2B, 3A e 3B).

A fim de confirmar a especificidade dos fragmentos obtidos, foi realizada a técnica de "Southern blot" seguida de hibridização, utilizando-se como sonda o clone FIV 34TF10, marcado com peroxidase, de acordo com o Kit ECL (Amersham). Foram hibridizados os produtos de PCR de quatro amostras que foram positivas no gel de agarose corado com brometo de etídeo $(11,12,16$ e 340), detectando-se bandas de aproximadamente 480 e 200pb (Fig. 4). Como controle positivo da hibridização, foram submetidos à eletroforese $\mathrm{e}$ posterior transferência para membrana de nylon, fragmentos obtidos a partir de PCR do clone FIV 34TF10.

\section{DISCUSSÃO}

A técnica de reação em cadeia da polimerase, PCR, tem demonstrado ser sensível e específica na detecção de animais infectados por FIV (Rimstad \& Ueland 1992, Dandekar et al. 1992). O número de amostras positivas, 15 num total de 40 analisadas, corresponde a um percentual de $37,5 \%$. Este valor é próximo ao descrito por Ishida et al. (1989), de 43,9\% em gatos clinicamente doentes. Embora as amostras tenham sido coletadas de animais com suspeita clínica de imunodeficiência, é importante salientar que outros fatores podem desencadear alterações no sistema imunológico. Entre as causas de origem viral, pode-se destacar o vírus da leucose felina (FeLV). Esse vírus era o único agente viral associado à imunodeficiência felina, até o isolamento do FIV em gatos domésticos. Alguns autores salientam que a co-infecção pelos dois retrovírus poderia ser favorável ao desenvolvimento de sintomatologia clínica mais precocemente (Pedersen et al. 1989).

A técnica de PCR, como técnica de detecção viral, vem sendo empregada extensivamente em medicina humana e com menor intensidade, devido ao custo e outras restrições de caráter prático, no diagnóstico veterinário. A importância 
da utilização desta técnica em medicina veterinária pode ser associada a situações específicas em que não seja possível detectar anticorpos induzidos pela infecção. Com relação ao FIV, já foi demonstrado que animais soronegativos podem reagir positivamente para detecção do DNA proviral (Dandekar et al. 1992).

A importância do diagnóstico de FIV em gatos domésticos também reside no aspecto zoonótico. Por exemplo, animais que apresentem comprometimento do sistema imunológico, poderiam eliminar maior quantidade de patógenos do que animais imunocompetentes, conforme demonstrado por Witt et al. (1997) em co-infecção com Toxoplasma gondii e por Malik et al. (1992) com Cryptococcus neoformans.

O presente trabalho teve por objetivo específico padronizar a detecção de DNA proviral de FIV a partir de amostras de sangue e de tecidos, além de associar estes resultados à presença de sinais clínicos de imunodeficiência. O FIV tem sido descrito como modelo animal para o HIV, em diferentes abordagens da patogenia (O'Neil et al. 1996); no desenvolvimento e avaliação de vacinas (Siebelink et al. 1995, Richardson et al. 1998) e de drogas antivirais (Smith et al. 1998). A possibilidade demonstrada pelos "primers" nas condições descritas, capazes de detectar o DNA proviral na primeira reação de PCR, indicaria que esta técnica seria válida para ser utilizada nas diferentes abordagens citadas acima, além de sua utilização no diagnóstico. Cabe salientar que duas reações de PCR, com "primers" externos e internos (denominada "nested PCR"), foram capazes de detectar um maior número de animais portadores do FIV. Como descrito na literatura, a "nested PCR" é uma técnica qualitativamente e quantitativamente superior à PCR simples. Há ganhos quanto à especificidade $\mathrm{e}$ à quantidade do material amplificado. Esta mesma técnica vem sendo utilizada com sucesso por nosso grupo para deteç̧ão de lentivírus em felinos selvagens (Leal \& Ravazzolo 1998).

Agradecimentos-- Ao Laboratório de Virologia Clínica da Faculdade de Veterinária, UFRGS, pelo fornecimento da maioria das amostras de sangue analisadas. Ao setor de Patologia da mesma Faculdade pelo fornecimento dos órgãos de animais necropsiados. Ao Prof. Schuch da Universidade Federal de Pelotas, RS, pelo envio de amostras de sangue. Ao Laboratório CENBIOTenzimas, do Centro de Biotecnologia da UFRGS pela enzima Taq DNA polimerase. Aos órgãos de fomento CNPq/RHAE, FAPERGS e CAPES.

\section{REFERÊNCIAS}

Barlough J.E., Ackley C.D., George J.H., Levy N., Aceyvedo R., Moore P.F., Rideout B.A., Cooper M.D.\& Pedersen N.C. 1992. Acquired immune disfunction in cats with experimentally induced feline immunodeficiency virus infection: comparison of short-term and long-term infections. J. Acq. Immun. Def. Syn. 4:219-227.

Barr M.C., Calle P.P., Roelke M.E. \& Scott F.W. 1989. Feline Immunodeficiency Virus infection in nondomestic felids. J. Zoo Wildl. Med. 20:265-272.

Brown W.E., Olmsted R.A., Martenson J.S. \& O‘Brien S.J. 1993. Exposure to FIV and FIPV in wild and captive cheetahs. Zoo Biology. 12:135-142.

Dandekar S., Beebe A.M., Barlough J., Phillips T., Elder J., Torten M. \& Pedersen N. 1992. Detection of feline immunodeficiency virus (FIV) nucleic acids in FIV-seronegative cats. J. Virol. 66:4040-4049.
Dow S.W., Poss M.L.\& Hoover E.A.1990. Feline Immunodeficiency Virus: a neurotropic lentivirus. J. Acq. Immun. Def. Syn. 3:658-668.

Hosie M.J. \& Jarret O. 1990. Serological reponses of cats to Feline Immunodeficiency Virus. AIDS 4:215-220.

Ishida T., Washizu T., Toriyabe K., Motoyoshi S., Tomoda I. \& Pedersen N.C. 1989. Feline immunodeficiency virus infection in cats of Japan. J. Am. Vet. Med. Assoc. 194:221-225.

Letcher J.D.\& O‘Connor T.P. 1991. Incidence of antibodies reacting to FIV in a population of Asian Lions. J. Zoo Wildl. Med. 22:324-329.

Leal E. \& Ravazzolo A.P. 1998. Detecção do vírus da imunodeficiência felina (FIV) em felídeos selvagens pertencentes à região neotropical, através da técnica de reação em cadeia da polimerase (PCR). Hora Vet., Porto Alegre, 101:57-60.

Malik R., Wigney D.I., Muir D.B., Gregory D.J. \& Love D.N. 1992. Cryptococcosis in cats: clinical and mycological assessment of 29 cases and evaluation of treatment using orally administered fluconazole. J. Med. Vet. Mycol. 30:133144.

Miyazawa T., Tomonaga K., Kawaguchi Y.\& Mikami T. 1994. The Genome of Immunodeficiency Virus. Archives of Virology 134:221-234.

Novotney C., English R.V., Housman J., Davidson M.G., Nasisse M.P., Jeng C.R., Davis W.C. \& Tompkins M.B. 1990. Lymphocyte population changes in cats naturally infected with feline immunodeficiency virus. AIDS 4:1213-1218.

Olmsted R.A., Barnes A.K., Yamamoto J.K., Hirsch V.M., Purcell R.H. \& Johnson P.R. 1989. Molecular clonning of feline immunodeficiency virus. Proc. Natl Acad. Sci. USA 86:2448-2452.

O'Neil L.L., Burkhard M.J. \& Hoover E.A. 1996. Frequent perinatal transmission of feline immunodeficiency virus by chronically infected cats. J. Virol. 70: 2894-2901.

Pedersen N.C., Ho E.W., Brown M.L.\& Yamamoto J.K. 1987. Isolation of a T lymphotropic virus from domestic cats with an Immunodeficiency-like Syndrome. Science 235:790-793.

Pedersen N., Torten M., Rideout B., Sparger E., Tonachini T., Luciw P.A., Ackley C. Levy N. \& Yamamoto J.K. 1989. Feline leukemia virus infection as a potentiating co-factor for the primary stage of experimentally induced feline immunodeficiency virus infection. Anais Quatrième Colloque des Cent Gardes, Paris, p. 167-171.

Richardson J., Moraillon A., Crespeau F., Baud S., Sonigo P. \& Pancino G. 1998. Delayed infection after immunization with a peptide from the transmembrane glycoprotein of the feline immunodeficiency virus. J. Virol. 72: 2406-2415.

Rimstad E. \& Ueland K. 1992. Deteccion of feline immunodeficiency virus by a nested polymerase chain reaction. J. Virological Methods 36:239-248.

Sambrook J., Fritsch E.F. \& Maniatis T. 1989. In: Molecular Cloning - A Laboratory Manual. Transfer of DNA from agarose gels to solid supports. 2:9.34-9.35.

Shelton G.H., Linenberger M.L., Grant C.K.\& Abkowitz J.L. 1990. Haematologic manifestations of Feline Immunodeficiency Virus infection. Blood 76:11041109.

Shelton G.H. 1991. Clinical manifestations of Feline Immunodeficiency Virus infection. Feline Pract. 19:14-20.

Siebelink K.H.J., Tijhaar E., Huisman R.C., Huisman W., Ronde A., Darby I.H., Francis M.J., Rimmelzwaan G.F. \& Osterhaus A.D.M.E. 1995. Enhancement of feline immunodeficiency virus infection after immunization with envelope glycoprotein subunit vaccines. J. Virol. 69: 3704-3711.

Smith R.A., Remington K.M., Preston B.D., Schinazi R.F. \& North T.W. 1998. Novel point mutation at position 156 of reverse transcriptase from feline immunodeficiency virus confers resistance to the combination of (-)-b-2', 3'-dideoxy-3'-thiacytidine and 3'-azido-3'-deoxythymidine. J. Virol. 72:23352340.

Talbott R.L., Sparger E.E., Lovelace K.M., Fitch W.M., Pedersen N.C., Luciw P.A. \& Elder J.H. 1989. Nucleotide sequence and genomic organization of feline immunodeficiency virus. Proc. Natl Acad. Sci. USA 86:5743-5747.

Thomas J.B., Robinson W.F.; Chadwick B.J.\& Jones P.S. 1993. Leukogram and 
biochemical abnormalities in naturally occurring FIV infection. J. Am. Anim. Hosp. Assoc. 29: 272-278.

Tompkins M.B.; Nelson P.D.; English R.V. \& Novotney R.C. 1991. Early events in the immunopathogenesis of feline retrovirus infections. J. Am. Vet. Med. Assoc. 199: 1311-1315.

Yamamoto J.K., Sparger E., Ho E.W., Anderson P.R., O‘Connor T.R., Mandell C.P., Lowenstine L.; Munn R. \& Pedersen N.C. 1988. Pathogenesis of experimentally induced Feline Immunodeficiency Virus infection in cats. Am. J. Vet. Res. 8:1246-1258.

Yamamoto J.K., Hansen H., Ho E.W., Morishita T.Y., Okuda T., Sawa T.R., Nakamura R.N. \& Pedersen N.C. 1989. Epidemiologic and clinical aspects of Feline Immunodeficiency Virus infection in cats from the continental United States and Canada and possible mode of transmission. J. Am. Vet. Med. Assoc. 194:213-220. 